\title{
Design and optimization of a compressed air energy storage (CAES) power plant by implementing genetic algorithm
}

\author{
S. Reza Shamshirgaran ${ }^{1}$, M. Ameri ${ }^{1}$, M. Khalaji ${ }^{2}$ and M. Hossein Ahmadi ${ }^{3}$,a \\ 1 Mechanical and Energy Engineering Dept., ACE, Shahid Beheshti University, Tehran, Iran \\ 2 Universiti Teknologi PETRONAS, Perak, 31750 Tronoh, Malaysia \\ 3 Department of Mechanical Engineering, Pardis Branch, Islamic Azad University, Pardis New City, Iran
}

Received 13 January 2015, Accepted 19 June 2015

\begin{abstract}
Today all engineering efforts are focused on the optimum utilization of available energy sources. The energy price is a critical subject regarding the present global conditions over the world. The strong penalties of $\mathrm{CO}_{2}$ generation have forced the designers to develop systems having the least pollution. Almost two thirds of electrical output energy of a conventional gas turbine (GT) is consumed by its compressor section, which is the main motivation for the development of Compressed Air Energy Storage (CAES) power plants. The main objective of this paper is to obtain the optimum parameters through which the CAES GT cycle can be designed effectively. The cost-benefit function as a target function has been maximized using the Genetic Algorithm. The Thermoflex software has been used for the CAES cycle modeling and design calculation. Meanwhile the sensitivity analysis results have shown that the net annual benefit and the discharge time duration of CAES plant decrease by increasing the fuel price. In addition, the optimal recuperator effectiveness increases with increasing the fuel price until it reaches its maximum value. Therefore, one can conclude that the future design modifications of the system as well as the variation in operation strategy of the existing plant will be based on the varying fuel price.
\end{abstract}

Key words: CAES / gas turbine / genetic algorithm / energy storage / optimization

\section{Introduction}

The concept of "energy storage" has been always an important issue to the human mind due to the limitation of the primary energy resources. The population growth and its resulting rise in energy demand along with the various types of energy demand resulted in developing the expeditious energy storage technologies and competent employment. One of the mechanical energy storage techniques takes advantage of the energy in the compressed air stored in a large reservoir underground or aboveground. This approach leads to the development of power plants called the compressed air energy storage (CAES) [1]. The CAES technology can even be more attractive when it is integrated with the renewable technologies such as solar (PV), wind, biomass and so forth. The first CAES power plant with 290 MW capacities has started its operation in 1979 in Huntorf, Germany and the next one with the capacity of $2 \times 110$ MW has been operating since 1991 in Alabama, US. Since then, several other power plants were constructed in Japan, Israel,

\footnotetext{
a Corresponding author:

mohammadhosein.ahmadi@gmail.com
}

Italy, Taiwan, and South Africa and some are being constructed in China, Malaysia, etc. The first hybrid power plant (CAES integrated wind) with 268 MW capacities was constructed and installed in Iowa, US where the wind farm production was 75-150 MW and called the Iowa energy stored park (IESP). The Norton project with the capacity of $2700 \mathrm{MW}(9 \times 300 \mathrm{MW})$ in Ohio, US is now under development and another $540 \mathrm{MW}(4 \times 135 \mathrm{MW}) \mathrm{CAES}$ power plant in Texas, US is under the construction $[2,3]$.

The CAES technology, in fact, is a modification of basic gas turbine (GT) technology in a way that the lowcost electricity is utilized for compressed air storage in an underground hole. Then, during the peak demand hours, the air is heated and expanded in a GT and the power is being generated. Similar to the technology of gas turbines, CAES is a reliable and available approach. So far, two power plants were constructed and installed; one in Germany with the capacity of $390 \mathrm{MW}$ for wind turbine and the second in the USA of $110 \mathrm{MW}$ turbine capacity. Owing to the limitation for the potential of the pumped hydro energy storage CAES, the technical description discussed in the early literature was confined to the load leveling and fuel saving utilization in combination with the coal-fired or nuclear power plants [4-9]. 

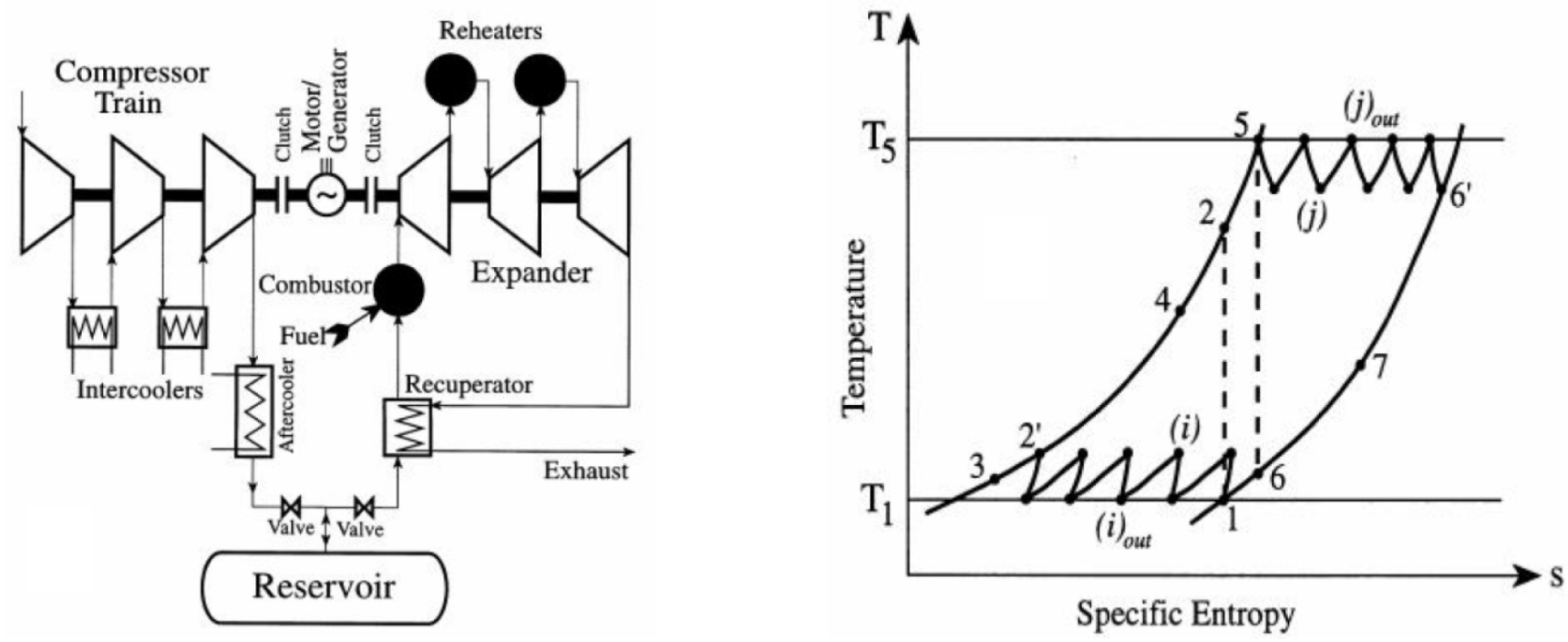

Fig. 1. (a) The schematic diagram of a CAES plant. (b) CAES thermodynamic cycle.

Bagdanavicius and Jenkins [10] carried out an analysis for the utilization potential of the waste heat generated within the compression stage in a CAES for two different systems: one for a CAES system and another for CAES with sensible thermal energy storage (TES) in connection with a district heating network. The analysis was performed based on the exergy and exergo-economics and it was obtained that the CAES with TES may be a valuable tool to balance the overall energy demand and energy supply.

The clutch system can be utilized in a CAES power plant to decouple the compressor and the turbine (expander) sections. In the off-peak mode, the motor/generator drives the compressor where the inexpensive off-peak energy is received from the electric grid. In this mode, the motor/generator acts as a motor and a clutch is used for the engagement to the compressor shaft. Underground large reservoirs such as salt cavern, aquifer and rock cavern are usually used as the storage medium for the compressed air. During the on-peak period, the compressed stored air leaves the reservoir to be used as the combustion air in a multistage modified gas turbine (turbo expander) and generates the peak electricity demand. In this mode, the motor/generator assembly works as a generator and the produced power from the turbine rotor is delivered completely to the generator terminals. So, the approach differs completely from the operation of conventional gas turbine. Through this technology, the electricity may be stored as compressed air, the efficiency of the gas turbine may be increased, and the emission may be reduced.

Designing a thermodynamic cycle for a CAES power plant to work in the optimum condition is one of the key points in the way of its development. In this paper, the thermodynamic design parameters for these power plants are introduced, but at first the governing equations for a cycle in a CAES power plant are considered. Such technical parameters along with the economical parameters are used to propose an optimization target function for the process. In fact, this target function represents a costbenefit function and the genetic algorithm (GA) is utilized to optimize it through utilization of the optimization tool (GA) of MATLAB software. Therefore, the optimum values of design parameters can be achieved which are usable in the process of design and modeling. The modeling step was accomplished by the Thermoflex software. The parametric sensitivity of the obtained parameters will assist the designer for modifications in the future design and help the operator to alter the operational parameters in the various conditions.

\section{The governing equations}

Because the CAES cycle is essentially a Brayton cycle, the governing equations may be derived utilizing the basic relations in the thermodynamic engineering. The CAES cycle differs from the Brayton cycle in the processes of compression in the compressor section and expansion in the expander section, because they do not take place at the same time. Hence, the interaction of these two sections must be taken into account using the conservation laws such as the conservation of mass and energy. The schematic diagram of a CAES system and its thermodynamic cycle are illustrated on the $T$-s diagram in Figure 1 [11].

The cycle of a CAES power plant includes the processes as follows (Fig. 1):

$1-2^{\prime}$ : Compression processes in the compressor train, including $(n-1)$ intercooling stages and one after cooling stage (the $n$th stage) $2^{\prime}-3$.

$2^{\prime}-3$ : After cooling process as mentioned before.

3-4: Isobar (approximately) preheating process in the recuperator.

4-5: Isobar (approximately) combustion process in the combustor. 
5-6': Expansion processes, including $(m-1)$ reheating stages.

6'-7: Isobar heat transfer process in the recuperator.

7-1: Isobar heat transfer process released through the exhaust to the ambient.

All the aforementioned processes from state 1 to state 3 take place when the power plant is operating in the "charging mode". In other words, the left clutch is engaged, and the motor/generator assembly acts as a motor to receive the power from the grid, drive the compressor, and charge the reservoir with compressed air. Next, the power plant operates in its discharging mode within the period of peak demand. In this mode, the right clutch is engaged and the motor/generator assembly works as a generator. All the aforementioned processes from state 3 to state 7 and the exhaust process $7-1$ take place in the discharging mode, net output power is generated and delivered to the grid by the generator. Equipment was employed to keep the initial required amount of the compressed air in the reservoir to maintain the pressure almost constant within the processes of charging and discharging. It should be noted that the state indices appearing in the parentheses stand for the intercooling or reheating stages within the process of compression and expansion, respectively. The thermal efficiency of a CAES is defined in a different way from the conventional form because it is actually a hybrid system which compresses the air and also generates electricity by consuming the fuel. The thermal efficiency for a CAES power plant is expressed as follows [11]:

$$
\eta_{t h}=\frac{w_{t}}{\frac{w_{c}}{\eta_{\mathrm{ext}}}+q_{f}}
$$

In Equation (1), $w_{t}$ and $w_{c}$ denote the specific work of the expansion and compression processes, respectively, $q_{f}$ stands for the specific heat during the combustion process in the combustor and reheaters, and $\eta_{\text {ext }}$ denotes the external thermal efficiency for the base load, power required for the compressor train, power plant such as coal-fired plant or wind farm. Therefore, the term $\frac{w_{c}}{\eta_{\text {ext }}}$ represents the required energy at the alternative base load plant to provide the compression work, $w_{c}$ in the CAES power plant. The storage effectiveness is defined as the ratio of the expansion to the compression work as:

$$
\beta=\frac{w_{t}}{w_{c}}
$$

The terminal isentropic temperature ratio, $R$, is defined as Equation (3) to formulate the optimum location for the reheaters and intercoolers [11]:

$$
R=\frac{T_{2}}{T_{1}}=\left(\frac{p_{2}}{p_{1}}\right)^{(k-1) / k}=r_{p}^{(k-1) / k}
$$

Therefore, for the compression and expansion processes, the optimum values for the specific works and for the combustor and reheaters, the specific heat of combustion, are formulated by:

$$
\begin{aligned}
w_{c}= & \frac{c_{p} T_{1}}{\eta_{c} \eta_{e l m}} n\left(\sigma_{c} R^{\frac{1}{n}}-1\right), \\
w_{t}= & c_{p} T_{1} \eta_{t} \eta_{e l m} r_{m t} m\left(1-\frac{\sigma_{t}}{R^{\frac{1}{m}}}\right) \\
q_{f}= & c_{p} T_{1} r_{m t}\left(\frac{\sigma_{h}}{R}-\varepsilon_{R C}\left(1+\eta_{t}\left(\frac{\sigma_{h}}{R}-1\right)\right)\right. \\
& \left.-\frac{r_{s t}}{r_{m t}}\left(1-\varepsilon_{R C}\right)+m\left(1-\frac{\sigma_{t}}{R^{\frac{1}{m}}}\right)\right)
\end{aligned}
$$

In Equations (4) and (5), $r_{s t}=T_{3} / T_{1}$ stands for the storage temperature ratio, $r_{m t}=T_{5} / T_{1}$ denotes the maximum temperature ratio, and $\eta_{t}$ and $\eta_{c}$ refer to the turbine and compressor efficiencies, respectively. In Equation (4), $\eta_{\text {elm }}$ represents the electromechanical efficiency to take the electrical and the mechanical losses into account. It can be shown that using the isentropic efficiencies instead of polytropic efficiencies, leads to only $5 \%$ error in the specific work estimation over a wide range of pressure ratio $\left(1<r_{p}<280\right)$. Hence, in order to simplify the analysis, the isentropic efficiencies may be used for the compression and expansion processes. The other parameters in Equations (4) and (5) are the number of intercoolers denoted by $(n-1)$ and the number of reheaters denoted by $(m-1)$. The parameter $\sigma$ represents the pressure losses where $\sigma_{t}$ refers to the global pressure losses factor (including pressure losses in valve, piping, reservoir, combustor and reheaters). The pressure losses in the intercoolers and recuperator are denoted by $\sigma_{c}$ and $\sigma_{h}$, respectively. Moreover, $\varepsilon_{R C}$ denotes the recuperator effectiveness. In the current research, the values for $c_{p}$ and all the aforementioned pressure losses are assumed to be constant. In this fashion, the energy storage effectiveness can be calculated by employing the following equation:

$$
\beta=\frac{\eta_{t} \eta_{c} \eta_{e l m} r_{m t} m\left(1-\frac{\sigma_{t}}{R^{\frac{1}{m}}}\right)}{n\left(\sigma_{c} R^{\frac{1}{n}}-1\right)}
$$

The specific fuel consumption is a key parameter which represents the mass of fuel to the produced power and it can be estimated via following equation:

$$
\begin{aligned}
\frac{\dot{m}_{f}}{\dot{W}_{t}}= & \frac{\dot{Q}_{f}}{H_{f} \dot{W}_{t}}=\frac{q_{f}}{H_{f} w_{t}} \\
= & \frac{1}{H_{f}}\left(1+\frac{\frac{\sigma_{h}}{R}}{m\left(1-\frac{\sigma_{t}}{R^{\frac{1}{m}}}\right)}\right. \\
& \left.-\frac{\varepsilon_{R C}\left(1+\eta_{t}\left(\frac{\sigma_{h}}{R}-1\right)\right)-\left(1-\varepsilon_{R C}\right) \frac{r_{s t}}{r_{m t}}}{m\left(1-\frac{\sigma_{t}}{R^{\frac{1}{m}}}\right)}\right)
\end{aligned}
$$

In Equation (7), $H_{f}$ stands for the lower heating value $(\mathrm{kWh} / \mathrm{kg})$. Introducing these relations in Equation (1) 


$$
\eta_{t h}=\frac{\eta_{t e l m} \eta_{c x l m} m\left(1-\frac{\sigma_{t}}{R^{\frac{1}{m}}}\right)}{\frac{1}{r_{m t}}\left(n\left(\sigma_{c} R^{\frac{1}{n}}-1\right)-\eta_{c x l m} r_{s t}\left(1-\varepsilon_{R C}\right)\right)+\eta_{c x l m}\left(\frac{\sigma_{h}}{R}-\varepsilon_{R C}\left(1+\eta_{t}\left(\frac{\sigma_{h}}{R}-1\right)\right)+m\left(1-\frac{\sigma_{t}}{R^{\frac{1}{m}}}\right)\right)}
$$

results in an expression for evaluation of the thermal efficiency for a CAES power plant as following as [11]:

$$
\begin{gathered}
\text { (See equation (8) above) } \\
\eta_{\text {telm }}=\eta_{t} \eta_{\text {elm }}, \eta_{c x l m}=\eta_{c} \eta_{\text {elm }} \eta_{\text {ext }}
\end{gathered}
$$

It can be observed from Equation (8) that the only independent technical parameters influencing the cycle performance for a CAES are $R, r_{m t}, \varepsilon_{R C}, r_{s t}, n$ and $m$. The parameter $R$ in the above expression has a mutual role in the numerator and denominator of the efficiency. Hence, it is concluded that an optimum value such as $R^{*}$ exists in the range between $R_{\min }$ and $R_{\max }$. The parameter $r_{m t}$ affects only the denominator of the efficiency equation which means that the optimum value of $r_{m t}$ is accomplished when the denominator reaches its minimum level. So, there must be a range for the optimum $r_{m t}$ as $r_{m t, \text { min }}<r_{m t}^{*}<r_{m t \text {, max }}$. Parameter $R$ represents the maximum pressure of the cycle so it is limited from the upper bound owing to the current available technology for the compressor and turbine manufacturing. Therefore, $R_{\text {max }}$ is set to 3.5 which is corresponds to $r_{p}=80$. Moreover, the lower bound for $R$ is chosen to be $\sigma_{h}$ since it is required that $p_{5}>p_{6 /}$. The maximum value for $r_{m t}$ is determined by the technology limitation for turbine blade inlet temperature. Hence, $r_{m t, \max }$ is set to 4.91. Furthermore, it is important that the minimum temperature of fluid passing through the turbine blades should not drop the icing temperature. So, thermodynamics can be used to show that $r_{m t, \min }$ is dependent on the value of $R$ [12]. It can be shown through the mathematical analysis of derivative for the denominator expression that the optimum value of $r_{m t}$ is the same as $r_{m t, \max }$ [12]. Hence, the following equations can be written:

$$
\begin{aligned}
& \left(r_{m t, \min }=1\right)<\left(r_{m t}^{*}=r_{m t, \max }=4.91\right) \\
& \left(R_{\min }=\sigma_{h}\right)<R^{*}<\left(R_{\max }=3.5\right)
\end{aligned}
$$

\section{The optimization process for optimum design of caes cycle}

Two key elements are necessary for any optimization process: Target or objective function and constraints of the optimization problem. The objective function, which is selected for CAES cycle optimization, is a cost-benefit function so that it involves all appropriate technical and economical parameters. These parameters are the problem variables, which will be controlled due to the thermodynamic of cycle as well as technological and economical limitations. The technical parameters have been identified in previous sections and the economic parameters are studied through next section [11].

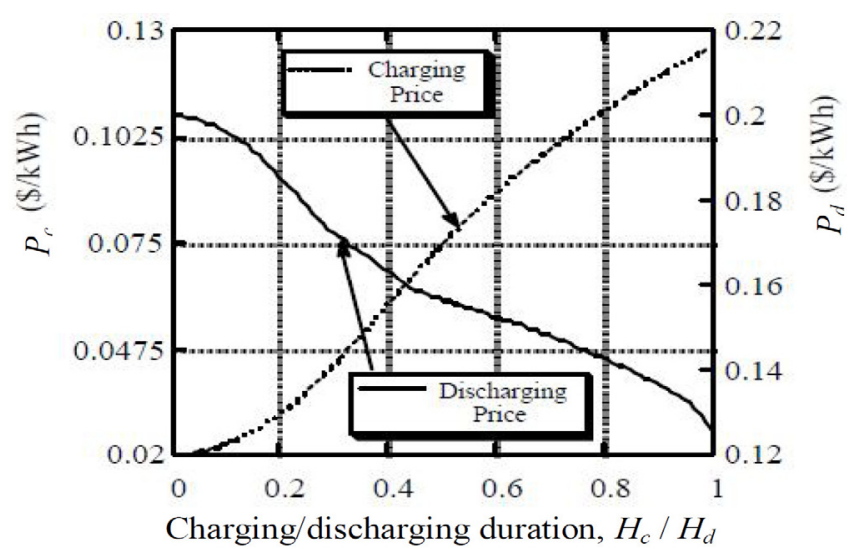

Fig. 2. The curve of charging and discharging price corresponding to a typical load demand curve.

\subsection{The objective function of optimization}

\subsubsection{Total revenue function}

The economics of a CAES plant depends on instantaneous price of electricity that depends on the load demand curve. In order to obtain the marginal prices of electricity, one should convert the load demand curve to the corresponding prices curve. The detail of this conversion method has been presented in reference [13]. Figure 2 shows a typical prices curve, which is obtained from an available sample load demand curve [11].

This figure represents the price of electricity generated, $P_{d}(\$ / \mathrm{kWh})$, in discharging duration $\left(h_{d}\right.$ or $H_{d}=$ $\left.h_{d} / 8760\right)$ in a CAES plant. Therefore, the total revenue from a CAES plant is $R e=P_{d} h_{d}$. Figure 2 shows also the price of electricity, $P c(\$ / \mathrm{kWh})$, which will be consumed by the compressor train in off-peak periods in charging duration $\left(h_{c}\right.$ or $\left.H_{c}=h_{c} / 8760\right)$ in a CAES plant. The charging price is included in CAES costs and will be discussed in following section. Here $h_{d}$ and $h_{c}$ represent time duration in turn of hours (h) for discharging and charging mode, correspondingly. The parameters $H_{d}$ and $H_{c}$ are normalized equivalent of $h_{d}$ and $h_{c}$, correspondingly.

\subsubsection{Total cost function}

The function of CAES plant total costs has been consisted from two main costs i.e. variable/running costs and fixed/capital ones. Each one of these components consists of its different components.

$C_{\text {tot }}=C_{\text {running }}+C_{\text {capital }}=S h_{d}+C_{1} K+C_{\mathrm{FOM}},(\$ / \mathrm{kW} \cdot \mathrm{yr})$ 
where $K, S, C_{I}$ and $C_{\mathrm{FOM}}$ stand for the capital recovery factor, running cost, capital cost and fixed operation and maintenance cost, correspondingly.

\subsubsection{Running costs}

The running cost component, $S$, has three cost parts:

$$
S=C_{c h}+C_{d}+C_{\mathrm{VOM}},(\$ / \mathrm{kWh})
$$

where $C_{c h}$ stands for the charging cost owing to off-peak electricity consumption by the compressor train in charging mode and depends on $P c$ in Figure 2. $C_{d}$ is the cost of fuel consumption by combustor and reheaters in discharging mode and $C_{\mathrm{VOM}}$ stands for variable operation and maintenance costs of a CAES plant, which is assumed constant. It is important to note that all of running costs are represented in $\$ / \mathrm{kWh}$ generated and thus $S$ is known as energy cost. As $P_{c}$ is represented in $\$ / \mathrm{kWh}$ compression in Figure 2, it should be converted to $\$ / \mathrm{kWh}$ generated:

$$
C_{c h}=P_{c} \frac{w_{c}}{w_{t}}=\frac{P_{c}}{\beta}=\frac{P_{c} n\left(\sigma_{c} R^{\frac{1}{n}}-1\right)}{\eta_{t} \eta_{c} \eta_{e l m} r_{m t} m\left(1-\sigma_{t} R^{\frac{1}{m}}\right)}
$$

It is obvious that the charging cost of a CAES plant is dependent on the main technical parameters of the cycle, i.e. $r_{m t}, R, m, n$ and $P_{c}\left(h_{c}\right)$. The other parameters are considered to be constant. Discharging cost is related to the cost of fuel, $P_{f}(\$ / \mathrm{kg}$-fuel), and specific fuel consummation i.e. $\frac{\dot{m}_{f}}{\dot{W}_{t}}(\mathrm{~kg}$ fuel $/ \mathrm{kWh}$ generated). Having the lower heating value of fuel, $H_{f}$ (kWh/kg-fuel), $C_{d}$ can be estimated as following as:

$$
\begin{aligned}
& C_{d}=P_{f} \frac{\dot{m}_{f}}{\dot{W}_{t}}=\frac{q_{f} P_{f}}{H_{f} w_{t}} \\
= & P_{H f}\left(1+\frac{\frac{\sigma_{h}}{R}-\varepsilon_{R C}\left(1+\eta_{t}\left(\frac{\sigma_{h}}{R}-1\right)\right)-\left(1-\varepsilon_{R C}\right) \frac{r_{s t}}{r_{m t}}}{m\left(1-\sigma_{t} R^{\frac{1}{m}}\right)}\right)
\end{aligned}
$$

where $P_{H f}$ denotes the cost of heat from combustion as $P_{H f}=\frac{P_{f}}{H_{f}}(\$ / \mathrm{kWh}$ heat of generated $)$.

\subsubsection{Capital costs}

Capital costs, $C_{I}$, of a CAES plant is related to investment cost of different installed equipments in the plant.

$$
C_{I}=r_{w} C_{c}+C_{t}+r_{g} C_{g}+r_{w} C_{i n}+C_{r e}+C_{R C}+C_{r}+C_{s}
$$

where $C_{c}, C_{t}, C_{g}, C_{i n}, C_{r e}, C_{R C}, C_{r}$ and $C_{s}$ are the capital cost of compressor, turbine, generator, intercooler, reheaters, recuperator, reservoir and supplementary equipments, correspondingly. Generally all capital costs of CAES plant represented in $\$ / \mathrm{kW}$ installed corresponding to turbine capacity. Hence, the conversion factors are used to convert the installed cost of compressor train and generator to installed cost of turbine as: $r_{w}=\frac{\dot{W}_{c}}{\dot{W}_{t}}, r_{g}=\frac{\dot{W}_{g}}{\dot{W}_{t}}$. The charging mode and discharging mode can be related by the following equation, which is resulted from the conservation of mass through the CAES cycle. The number of operating cycles per year is taken to be $M$.

$$
\begin{aligned}
\frac{\dot{m}_{c} h_{c}}{M}=\frac{\dot{m}_{t} h_{d}}{M} \Rightarrow r_{h}= & \frac{h_{d}}{h_{c}}=\frac{\dot{W}_{c} w_{c}}{\dot{W}_{t} w_{t}} \\
& \text { and } r_{w}=\frac{r_{h}}{\beta} \Rightarrow r_{h}=r_{w} \beta
\end{aligned}
$$

\subsubsection{The net benefit}

The net benefit, $B$, from the CAES plant generation is estimated by subtracting the total costs from the total revenue:

$$
B=\left(P_{d}-S\right) h_{d}-C_{I} K-C_{\mathrm{FOM}}
$$

It should be noted that one can use the yield function as $Y=B / C_{\text {tot }}$ instead of the net benefit function and the results will be the same.

\subsection{Optimization of objective function}

The objective function is net benefit $(B)$. As it is observed from the relations, the involved main parameters are: $r_{m t}, R, r_{h}, h_{\mathrm{d}}, \varepsilon_{R C}, m, n$. These parameters are decision variables of optimization problem which represent the design space and should be optimized. Therefore, the optimization problem is considered as following as:

$$
\operatorname{Max} B=f\left(r_{m t}, R, r_{h}, h_{\mathrm{d}}, \varepsilon_{R C}, m, n\right)
$$

Subject to:

$$
\begin{aligned}
& 1 \leq r_{m t} \leq 4.91 \\
& 1 \leq R \leq 3.5 \\
& 0 \leq r_{h} \leq 100 \\
& 0 \leq H_{d} \leq 1 \\
& 0 \leq \varepsilon_{R C} \leq 1 \\
& 1 \leq m \leq m_{\max } \\
& 1 \leq n \leq n_{\max }
\end{aligned}
$$

Throughout this research, the MATLAB software has been selected for optimization process due to its ability and interesting facilities. Genetic algorithm (GA) is one of the powerful toolboxes of MATLAB for optimization application [14]. The completed optimization problem has been fitted into a function form in MATLAB software. The input cost data have been taken from an available data set, which has been presented in reference [15]. The optimization result for the value of best function after 70 times of iteration has been shown in Figure 3. Therefore the maximum value of net annual 


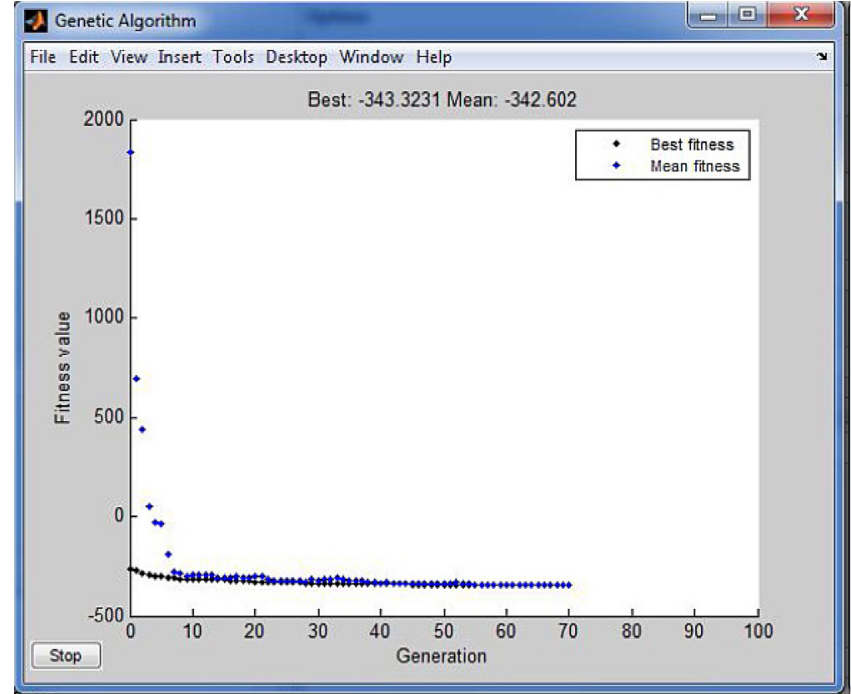

Fig. 3. The result of optimization process for best fitness.

benefit is obtained to be $343.3 \$ / \mathrm{kW}$.yr for the following optimum values: $r_{m t}^{*}=4.91, R^{*}=3.2, r_{h}^{*}=4.1$, $H_{d}^{*}=0.79, \varepsilon_{R C}^{*}=0.76, m^{*}=2, n^{*}=4$.

The results mean that for a typical existing condition, CAES cycle designer selects a recuperator, for example, which has an effectiveness of 0.76 . The selection of a compressor providing an isentropic terminal temperature ratio of 3.2 is the best option. The other optimum parameters are estimated based on the optimized design parameters: $r_{p}^{*}=\left(R^{*}\right)^{\frac{k}{k-1}}=58.6, \beta=2.2$, $r_{w}^{*}=\frac{r_{h}^{*}}{\beta}=1.86, H_{c h}^{*}=\frac{H_{d}^{*}}{r_{h}^{*}}=0.19$. It means that designer should select a compressor with the capacity of 1.86 times higher than the turbine capacity. The CAES plant in supposed conditions should operate $6920 \mathrm{~h}$ per year in discharging mode and $1664 \mathrm{~h}$ per year in charging mode. The important point that should not be missed, is that the results of optimization process especially $r_{h}$ and hence $r_{w}$ are very sensitive to the load demand curve and therefore to the marginal prices curve. In other words, it may be a smaller compressor obtained rather than the turbine in view of capacity value if the load demand becomes different.

\section{Modeling the caes cycle}

Using the optimum design parameters obtained in previous section, the modeling of CAES cycle is possible. The Thermoflex, which is a module of THERMOFLOW software, has been chosen for this purpose. It is one of the best existing softwares for modeling the process plants especially for different types of power plants [16]. Figure 4 shows the CAES plant which has been modeled in Thermoflex.

The specification of each component of the CAES cycle is calculated based on the optimum design parameters. Therefore the thermal efficiency of CAES cycle is equal to 0.51 . The optimal location of intercoolers is estimated based on the overall pressure ratio of compressor train (58.6) according to the method presented in reference [17]. The model has been run in Thermoflex and the outputs have shown to be acceptable.

\section{Verification of caes model}

\subsection{Technical evaluation}

There are some technical indices for the performance evaluation of CAES plants [3] which three of them are the most important ones. The first index is the heat rate which is in the range of $4200-4800 \mathrm{~kJ} / \mathrm{kWh}$ for typical plants and the more important point is that its value does not vary significantly even at partial loads. The value of heat rate for modeled cycle is $4647 \mathrm{~kJ} / \mathrm{kWh}$ which is one of the output results of Thermoflex. The model has been run for partial loads from $10 \%$ to $100 \%$ of full load. The heat rate has been found to be 4717 at $10 \%$ of full load. Thus, the model works correctly because the change of cycle heat rate is not significant. The second index is charging electricity ratio (CER) which is defined as CER = $\mathrm{kWh}$ output $/ \mathrm{kWh}$ input. The value of CER varies typically in the range of 1.2-2.8 [3] and CER value for CAES model is 2.2 which is in the acceptable range. The third index is energy ratio (ER) defined as the inverse of CER. The energy ratio of the model is 0.45 which means that in order to obtain $1 \mathrm{kWh}$ energy from CAES plant it is necessary to give $0.45 \mathrm{kWh}$ energy to the plant cycle at the mentioned conditions.

\subsection{Economical evaluation}

Generally, there are three indices for the economic evaluation of a plant i.e. net present value $(N P V)$, internal rate of return $(I R R)$ and capital payback period $(C P P)$ [18]. The value of these indices has been calculated for the model based on the present worth of all revenue and cost components, which are presented in Table 1.

It is assumed that the value of useful life of the plant and annual discount rate have to be 30 and $12 \%$, correspondingly. Therefore, the value of capital recovery factor, $K$, would be equal to $0.124, N P V=347.9 \$ / \mathrm{kW}$, $I R R=27.5 \%$ and $C P P=5.05$. As the value of $N P V$ is positive, thus the project will be a profitable one. The value of $I R R$ is higher than the annual discount rate. Therefore, it indicates that the design is profitable. The value of 5.05 year for $C P P$ is accomplishment and confirms the economical feature of the design.

\section{Sensitivity analysis}

It is clear that the various fuels that can be used in the combustion chamber and reheaters, have their special price. On the other hand, the price of fuel may be 


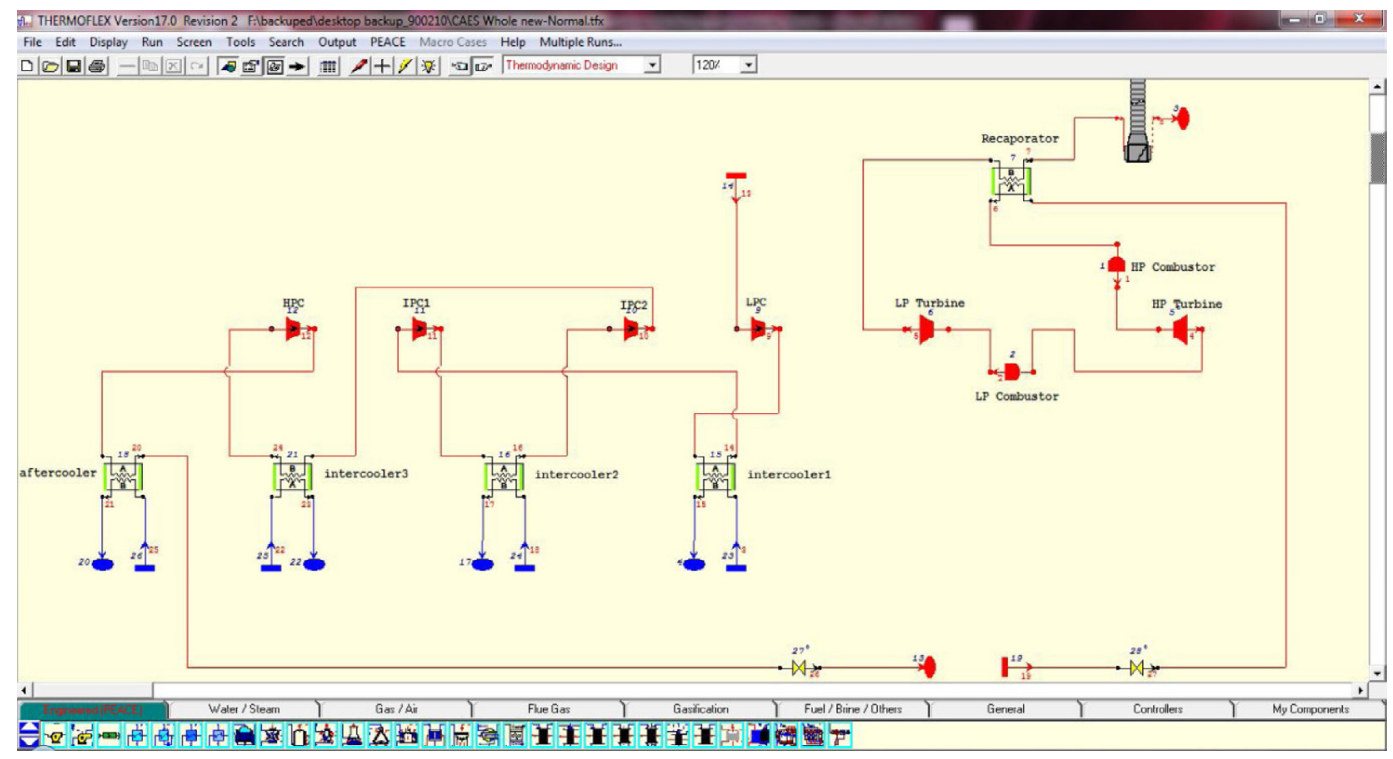

Fig. 4. The modeled CAES plant in Thermoflex software.

Table 1. The present worth of all revenue and cost components of the CAES plant.

\begin{tabular}{ccc}
\hline $\begin{array}{c}\text { Income } / \text { cost } \\
\text { component }\end{array}$ & Value WM] & Present worth $[\$ / \mathrm{kW}]$ \\
\hline$C_{I}$ & 530 & 530 \\
$C_{\mathrm{FOM}}$ & 4.74 & 38.2 \\
$C_{c h}$ & 31.43 & 253.5 \\
$C_{d}$ & 159.84 & 1289.03 \\
$C_{\mathrm{FOM}}$ & 1.6 & 12.9 \\
$R e$ & 343.6 & 2771 \\
\hline
\end{tabular}

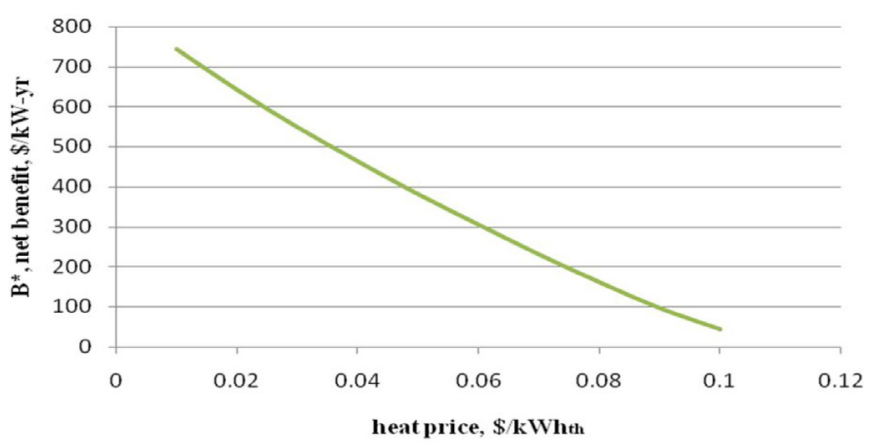

Fig. 5. The variation of net benefit of CAES plant based on the heat price.

changed in the different times. Hence, the designer should check the variation of technical parameters of CAES cycle for the change of fuel price, $P_{f}$, or heat price, $P_{h f}$. In this way the future design modification or present necessary changes in operation strategy will be clear. Figures 5 and 6 show the variation of net benefit of the plant, recuperator effectiveness and discharging duration time based on the heat price. According to Figure 5 the net benefit from the CAES plant decreases as the heat/fuel

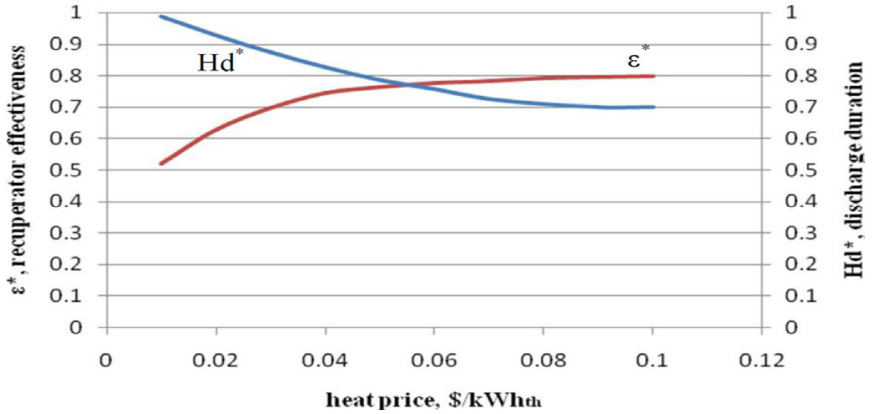

Fig. 6. The variation of recuperator effectiveness and discharging duration based on the heat price.

price increases. Figure 6 represents that the designer have to select a larger recuperator with increasing the fuel price until it reaches to $0.08 \$ / \mathrm{kWh}_{\mathrm{th}}$. However, after this value the effectiveness remains constant, therefore the design will not be so profitable. Furthermore, the aforementioned figure illustrates the optimized discharging duration time that has a descending trend when the fuel price increases. It can be observed that after the fuel price of $0.08 \$ / \mathrm{kWh}_{\mathrm{th}}$, the value of $H_{d}$ becomes constant.

\section{Conclusions}

The approach explained here for the design of a CAES cycle is a global approach that can be employed for any situation such as cost data and load demand curve. The modeling of a CAES cycle in Thermoflex has many advantages because this software provides the possibility of the complete evaluation of the CAES plant in design and off-design mode, at full load and part load, etc. The results of optimization process will define the compressor capacity and hence the required capacity of a wind farm, 
solar (PV) plant, nuclear or any possible fossil fuel or renewable power plant for providing the off-peak electricity for compressor train.

Acknowledgements. Originally presented in 4th International Conference on Sustainable Energy and Environment.

\section{References}

[1] B. Kilkis, Energy Storage Systems, NATO ASI Ser. E: Appl. Sci. 167 (1989)

[2] V. Fthenakis, Proceeding of 2nd Compressed Air Energy Storage (CAES) Conference and Workshop, Columbia University, Columbia, US, 2010

[3] S. Succar, Compressed Air Energy Storage: Theory, Resources and Applications for Wind Power, Princeton Univ. Environmental Institute, Princeton, US, 2008

[4] Y.S.H. Najjar, M.S. Zaamout, Performance analysis of compressed air energy storage (CAES) plant for dry regions, Energy Convers. Manage. 39 (1998) 1503-1511

[5] H. Lund, G. Salgi, The role of compressed air energy storage (CAES) in future sustainable energy systems, Energy Convers. Manage. 50 (2009) 1172-1179

[6] J.J. Proczka, K. Muralidharan, D. Villela, J.H. Simmons, G. Frantziskonis, Guidelines for the pressure and efficient sizing of pressure vessels for compressed air energy storage, Energy Convers. Manage. 65 (2013) 597-605

[7] Ke Yang, Yuan Zhang, Xuemei Li, Jianzhong Xu, Theoretical evaluation on the impact of heat exchanger in Advanced Adiabatic Compressed Air Energy Storage system, Energy Convers. Manage. 86 (2014) 1031-1044

[8] S. Wang, G. Chen, M. Fang, Q. Wang, A new Compressed Air Energy Storage refrigeration system, Energy Convers. Manage. 47 (2006) 3408-3416
[9] Y. Luo, L. Shi, G. Tu, Optimal sizing and control strategy of isolated grid with wind power and energy storage system, Energy Convers. Manage. 80 (2014) 407-415

[10] A. Bagdanavicius, N. Jenkins, Exergy and exergoeconomic analysis of a Compressed Air Energy Storage combined with a district energy system, Energy Convers. Manage. 77 (2014) 432-440

[11] P. Vadasz, Compressed Air Energy Storage: Optimal Performance and Techno-Economical Indices, Int. J. Appl. Thermodyn. 2 (1999) 69-80

[12] P. Vadasz, A Performance Analysis of a Compressed Air Energy Storage System in Aquifer, Israel J. Technol. 25 (1989) 13-21

[13] P. Vadasz, A Second-Order Marginal Costs Approximation for Energy Storage Charging and Discharging Price Functions, Trans. ASME 111 (1989) 154-159

[14] M.H. Ahmadi, M.A. Ahmadi, M. Mehrpooya, H. Hosseinzade, M. Feidt, Thermodynamic and thermoeconomic analysis and optimization of performance of irreversible four-temperature-level absorption refrigeration, Energy Conversion and Management 88 (2014) 1051-1059

[15] P. Vadasz, Analysis and Optimization of a Compressed Air Energy Storage System, Int. Gas Turbine Conference and Exhibit, Dusseldorf, Germany, 1986

[16] Thermoflex User Manual, Thermoflow Inc., US, 2007, available at: www.thermoflow.com

[17] P. Vadasz, On the Optimal Location and Number of Intercoolers in a Real Compression Process, Gas Turbine and Aeroengine Congress, Amsterdam, Netherland, 1988

[18] Y. Saboohi, Analysis of Energy Systems, Energy Engineering Department, Sharif Univ., Tehran, Iran, 2000 